\title{
Phlebotomine sandflies (Diptera: Psychodidae) from Lábrea, state of Amazonas, Brazil, with a description of Evandromyia (Aldamyia) apurinan Shimabukuro, Figueira \& Silva, sp. nov.
}

\author{
Elder Augusto Guimarães Figueira', Glacicleide Silva', \\ Érica Cristina da Silva Chagas', Paloma Helena Fernandes Shimabukuro ${ }^{2,3 /+}$ \\ ${ }^{1}$ Fundação de Vigilância em Saúde do Amazonas, Manaus, AM, Brasil nstituto Leônidas e Maria Deane-Fiocruz, Manaus, AM, Brasil \\ ${ }^{3}$ Centro de Pesquisas René Rachou-Fiocruz, Belo Horizonte, MG, Brasil
}

An entomological survey was conducted from July-December 2009 and September-December 2010, as part of the epidemiological monitoring of American cutaneous leishmaniasis (ACL) in the municipality of Lábrea, state of Amazonas (AM), Brazil. Sandflies were collected using CDC light traps installed in intra and peridomiciliary locations, as well as the border of forested areas around houses where autochthonous cases of ACL were recorded. A total of 510 sandflies belonging to 26 species were collected. The most abundant species was Nyssomyia antunesi (44.5\%) followed by Evandromyia walkeri (10.6\%) and Micropygomyia rorotaensis (9.8\%). Here we also describe Evandromyia (Aldamyia) apurinan sp. nov. and report new records for Trichophoromyia flochi and Evandromyia sipani in AM and Brazil, respectively. Our results describe the composition of the sandfly fauna in the south of AM and suggest $\mathrm{Ny}$. antunesi as the putative vector in the transmission of Leishmania in this area of the Amazon Region.

Key words: Amazon - Evandromyia apurinan - leishmaniasis - new records - Nyssomyia antunesi - vectors

The Amazon Region accounts for the largest diversity of Leishmania Ross, 1903 parasites and sandfly vector species in the Neotropical Region (Rangel \& Lainson 2003b, Rotureau 2006). Of the 30 described species of Leishmania in the world, at least seven have been found infecting humans in the Amazon Region, while at least 15 sandfly species are known or putative vectors (Rotureau 2006). In the Amazon, the transmission cycle is maintained between wild animal reservoirs - which typically present non-pathogenic Leishmania infection - and sandflies.

In Brazil, the region to the north of the rivers Negro and Amazonas, including the states of Amazonas (AM), Roraima, Pará (PA) and Amapá, Leishmania (Viannia) guyanensis Floch, 1954 is the main etiological agent of American cutaneous leishmaniasis (ACL) and it is associated with most cases of human leishmaniasis (> 50\%) recorded for the whole Amazon (Arias \& Freitas 1978, Romero et al. 2002, Rotureau 2006). In these states, human infections typically occur as a result of human activity (hunting, fishing, farming, mining, civil construction etc.), resulting from the exploitation and/or destruction of primary tropical forest.

In contrast, little is known about the epidemiology of ACL in the Amazonian Region, south of the rivers Negro and Amazonas (Arias \& Freitas 1978, Justiniano et al. 2004). Recently, Guerra et al. (2011) described the epidemiology of mucosal leishmaniasis (ML) in the Ama-

+ Corresponding author: phfs@yahoo.com

Received 26 June 2012

Accepted 13 November 2012 zon Region and not only found a higher prevalence of this form of the disease south of the river, but also reported similar distribution of Leishmania species among patients from north and south of the Amazonas River. However, the species of Leishmania parasites infecting humans, the non-human animal reservoir hosts and the sandfly vectors involved in transmission of cutaneous leishmaniasis in this region have not yet been identified.

The municipality of Lábrea is located in the south region of AM and has been recording an increasing number of cases of ACL (MS/SINAN 2012). In Lábrea, ACL is associated with sustainable subsistence and economic activities such as Brazil-nut collection, latex extraction, agriculture, fishing and hunting, performed mostly by indigenous and traditional riverine communities (Guerra et al. 2011). The objective of this work was to identify the sandfly fauna associated with autochthonous cases of ACL in Lábrea as part of the entomological monitoring program for leishmaniasis performed by the Amazonas Health Surveillance Foundation (FVS/AM).

\section{MATERIALS AND METHODS}

Study area - The municipality of Lábrea is located in the southern of AM, close to the border with state of Rondônia (RO) and between two main rivers (Purús and Madeira). The population is 37,574 inhabitants and the territorial area is $68,233.96 \mathrm{~km}^{2}$ (IBGE 2012). Lábrea, along with the municipalities of Canutama, Tapauá and Pauini, comprises the area known as the Middle Purús. The main economic activity is Brazil nut collection, performed by indigenous and non-indigenous local populations, making Lábrea the second biggest producer in AM (IBGE 2012).

Sandfly collection - Sandflies were collected from July-December 2009 and September-December 2010, using modified CDC light traps placed in intra and peri- 
domiciliary locations, as well as along the border of forested areas around the houses where autochthonous cases of human ACL were recorded. The four sites studied were: Vila Falcão, a neighbourhood in Lábrea, Apairal, a rural settlement along the Trans-Amazonian Road BR-230 and Aldeia Castanheira and Aldeia Irmã Cleusa, settlements of indigenous people of the Apurinã ethinc group, located in the Caititu Indian Reserve.

Specimens were placed in containers with ethanol $70 \%$. At the FVS/AM laboratory, the insects were separated and sandflies were prepared according to the method described by Forattini (1973) and mounted on microscope slides in Canada Balsam medium.

The specimens were identified and measured using an AxioScope A1 Zeiss ${ }^{\circledR}$ microscope with AxioVision ${ }^{\circledR}$ software. All measurements are given in micrometers. The average measurements and standard deviation for paratypes are given in brackets. For definitions of the terminology used to describe sandfly morphology and a key for identification of all Evandromyia species see Bermúdez et al. (1991) and Galati (2003).

\section{RESULTS}

Evandromyia (Aldamyia) apurinan Shimabukuro, Figueira and Silva, sp. nov.

(Figs 1-13)

Description - Holotype (male): total body length: $2,309(2,346 \pm 156 ; n=12)$. Predominantly light brown, with light brown pronotum, paratergite and mesonotum and thoracic pleura, except for brown katepimeron, katepisternum and coxae, but without clear contrast.

Head (Fig. 1): length $348(341 \pm 18 ; \mathrm{n}=12)$, width $300(304 \pm 6 ; \mathrm{n}=12)$. Eyes: length $166(165 \pm 9 ; \mathrm{n}=12)$,
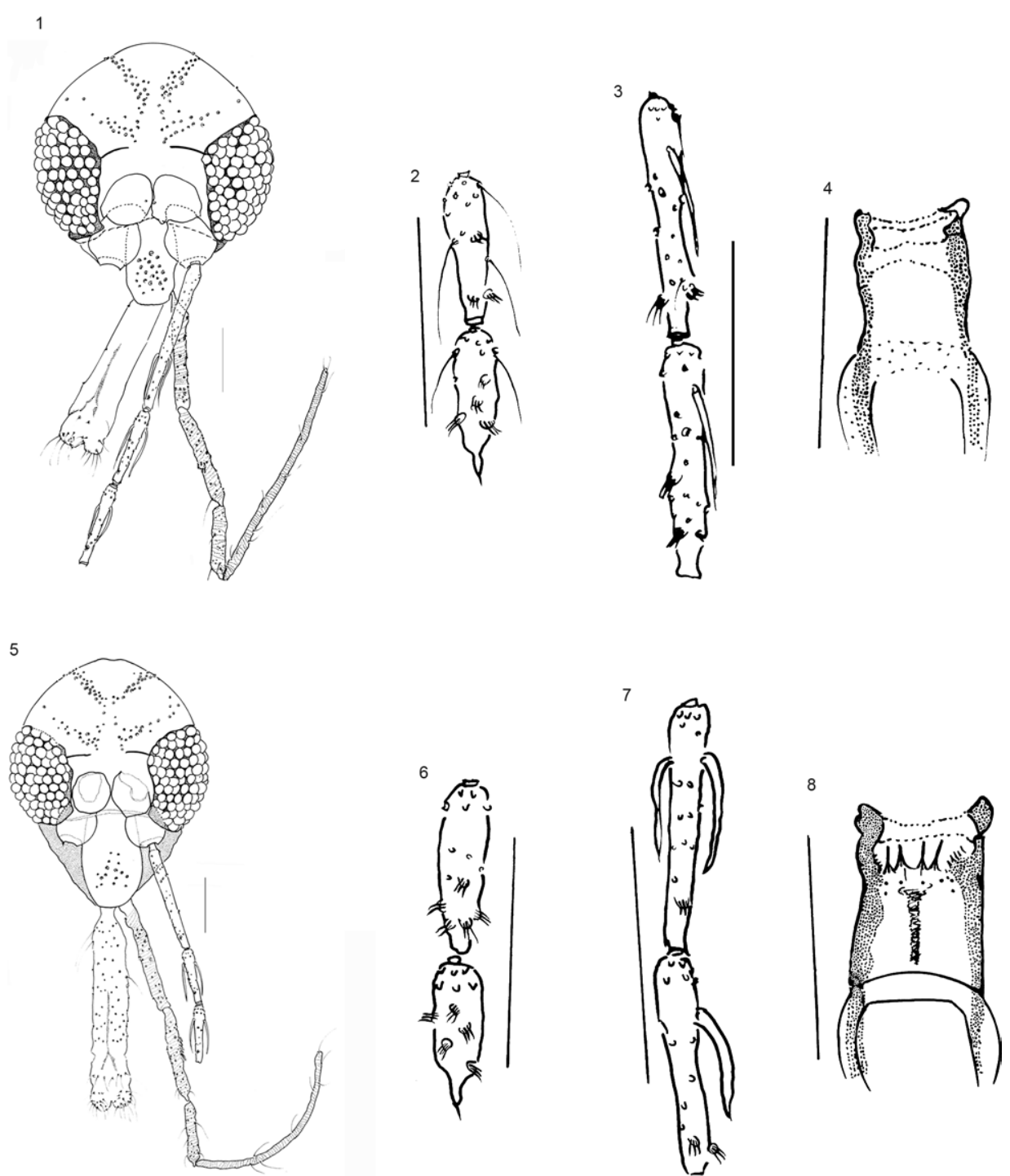

Figs 1-8: Evandromyia (Aldamyia) apurinan sp. nov. Holotype male: 1: head, frontal view; 2: antennomeres XV and XVI; 3: antennomeres XIII and XIV $(B a r=100 \mu \mathrm{m})$; 4: cibarium $(B a r=50 \mu \mathrm{m})$; allotype female: 5: head, frontal view; 6: antennomeres XV and XVI; 7: antennomeres XIII and XIV $($ Bar $=100 \mu \mathrm{m}) ; 8:$ cibarium $($ Bar $=50 \mu \mathrm{m})$. 
width $88(100 \pm 6 ; n=12)$ (frontal view). Interocular distance $126(122 \pm 8 ; n=12)$. Interocular suture incomplete (not reaching the antennal suture). Clypeus: length 127 $(115 \pm 7 ; n=12)$, width $63(62 \pm 4 ; n=12)$. Antennomere lengths: AIII (Fig. 1) $202(220 \pm 13 ; \mathrm{n}=12)$, AIV (Fig. 1) $102(112 \pm 6 ; n=12)$, AV (Fig. 1) $108(115 \pm 6 ; n=12)$, AXV (Fig. 2) $60(61 \pm 3 ; n=9)$ and AXVI (Fig. 2) 57 (55 $\pm 4 ; \mathrm{n}=9$ ). Antennal formula AIII-AXV 2, AXVI 0, ascoids without posterior spur, anterior prolongation long reaching the distal end of the flagellomere, pre-apical papilla present on AIII-AV 1 (Fig. 1), AVI-AXII 0 and AXIII 3, AXIV 5, AXV 6, AXVI 5 (Figs 2, 3). Length of the palpomeres: I $27(30 \pm 3 ; \mathrm{n}=12)$, II $106(116 \pm 7 ; \mathrm{n}=$ 12), III 137 (142 \pm 6; $\mathrm{n}=12)$, IV 91 ( $93 \pm 5 ; \mathrm{n}=12)$, V 280 $(311 \pm 26 ; n=11)$. Palpal formula: 1.4.2.3.5. Newstead's spines distributed in the middle portion of palpomere III and absent from palpomere II. Labroepipharynx 186 $(209 \pm 10 ; n=12)$ long. Labial sutures united. Cibarium reduced without teeth (Fig. 4).

Cervix: ventrocervical sensilla present.

Thorax: mesonotum length $428(463 \pm 30 ; \mathrm{n}=12)$. Pleura with four proepimeral setae $(3-5 ; \mathrm{n}=12)$ and 18 upper anepisternal setae $(14-27 ; \mathrm{n}=12)$ and without metaepisternal setae. Setae present on the anterior katepis-
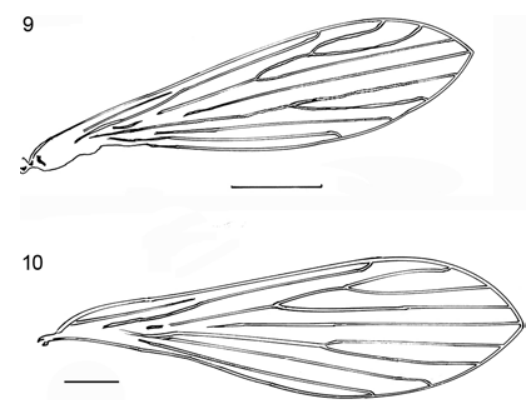

11

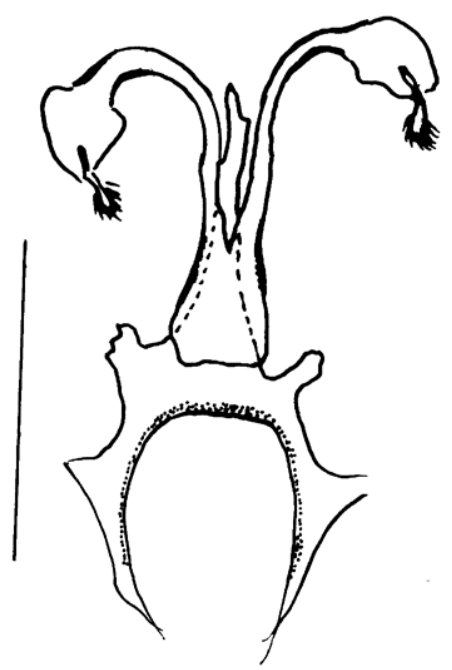

Figs 9-11: Evandromyia (Aldamyia) apurinan sp. nov. Holotype male: 9: wing; allotype female: 10: wing; 11: spermathecae. Bar $=100 \mu \mathrm{m}$. ternum margin. Incomplete suture between katepimeron and metepisternum present. Wing (Fig. 9): length 1,716 $(1,799 \pm 66 ; \mathrm{n}=12)$, width $436(461 \pm 28 ; \mathrm{n}=11)$. Length of vein sections: alpha $314(364 \pm 30 ; \mathrm{n}=12)$, beta 231 $(266 \pm 28 ; \mathrm{n}=12)$, gamma $307(263 \pm 39 ; \mathrm{n}=12)$, delta $58(92 \pm 29 ; \mathrm{n}=12)$, pi $154(132 \pm 26 ; \mathrm{n}=12), \mathrm{R} 51,149$ $(1,167 \pm 42 ; n=12)$. Legs (measures based on paratype 7) foreleg: length of femora 687, tibiae 717, basitarsi 404 and tarsi $\mathrm{II}+\mathrm{III}+\mathrm{IV}+\mathrm{V}$ 539; midleg: length of femora 677, tibiae 867, basitarsi 473 and tarsi II+III+IV+V 569; hindleg: length of femora 739 .

Abdomen: $1,397(1,392 \pm 119 ; \mathrm{n}=12)$ long. Tergal papilla present on tergites 5 and 6 . Terminalia (Fig. 12): gonostyle $144(137 \pm 6 ; n=12)$ long, with four spines; the spines having the following disposition: one apical, the upper external located near the apical spine and the lower external located on the apical third region of the gonostyle, the internal on the middle of the gonostyle. Gonocoxite (277 long x 82 wide) $(292 \pm 17$ x $88 \pm 7$; n $=12$, with a basal tuft with eight thin setae (8-10; $\mathrm{n}$ $=12$ ), presence of a sclerotized longitudinal strip on the internal margin of the gonocoxite, presence of a second tuft of setae implanted loosely on the middle of the gonocoxite. Paramere long and simple, dorsal margin length $174(174 \pm 12 ; \mathrm{n}=12)$, ventral margin length $215(180 \pm 26 ; n=12)$ with setae along its apical half. Forked aedeagus, dorsal margin length of ventral branch $55(55 \pm 13 ; \mathrm{n}=9)$ and ventral margin length of ventral branch $75(63 \pm 13 ; n=11)$. Lateral lobe length $354(348 \pm 12 ; \mathrm{n}=12)$, width $25(25 \pm 1 ; \mathrm{n}=12)$. Genital pump: length $189(197 \pm 8 ; \mathrm{n}=12)$, piston length 129 $(132 \pm 8 ; \mathrm{n}=12)$ and chamber length $63(61 \pm 4 ; \mathrm{n}=12)$. Genital filaments length $250(260 \pm 8 ; n=12)$. Slender genital ducts with a tooth at the apex (Fig. 13). Cercus 10 long $(9 \pm 1 ; \mathrm{n}=12)$.

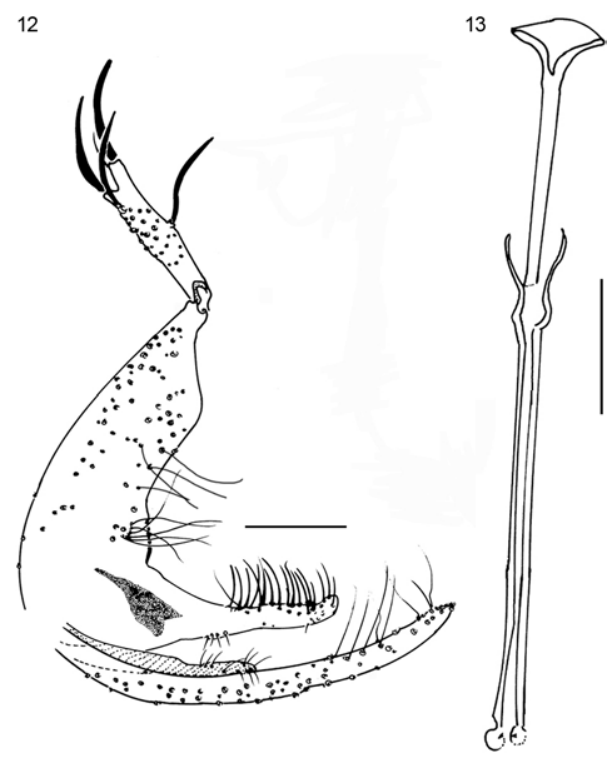

Figs 12, 13: Evandromyia (Aldamyia) apurinan sp. nov. Holotype male: 12 : terminalia; 13 : ejaculatory ducts. Bar $=100 \mu \mathrm{m}$. 
Allotype (female): total body length 2,305 $(2,260 \pm$ $153 ; \mathrm{n}=12)$. General colouration as for the male. Head (Fig. 5): length 394 (399 $\pm 9 ; \mathrm{n}=12)$, width $319(322 \pm$ $13 ; n=12)$. Eyes: length $166(175 \pm 11 ; n=12)$, width 95 $(96 \pm 5 ; \mathrm{n}=11)$ (frontal view). Interocular suture incomplete (not reaching the antennal suture). Interocular distance $129(133 \pm 11 ; \mathrm{n}=11)$. Clypeus: length $152(157 \pm$ $7 ; \mathrm{n}=12)$, width $99(95 \pm 6 ; \mathrm{n}=11)$. Flagellomeres: AIII (Fig. 5) 174 (186 $\pm 12 ; n=12)$, AIV (Fig. 5) 92 (96 \pm 4; $\mathrm{n}=12)$, AV 95 (Fig. 5) $(98 \pm 5 ; \mathrm{n}=11)$, AXV (Fig. 6) 63 $(62 \pm 2 ; n=7)$ and AXVI (Fig. 6) $53(53 \pm 3 ; n=7)$. Antennal formula AIII-AXV 2, AXVI 0, ascoids without posterior spur, anterior prolongation long reaching the distal end of the flagellomere, pre-apical papilla present on AIII-AV 1 (Fig. 5), AVI-AX 0 and AXI 1, AXII 2, AXIII 2, AXIV 5, AXV 6, AXVI 5 (Figs 6, 7). Palpomere length: I $38(41 \pm 16 ; \mathrm{n}=12)$, II $139(144 \pm 8 ; \mathrm{n}=12)$, III $150(155 \pm 8 ; \mathrm{n}=12)$, IV $96(97 \pm 6 ; \mathrm{n}=10), \mathrm{V} 317$ $(314 \pm 16 ; \mathrm{n}=8)$. Palpal formula: 1.4.2.3.5. Newstead's spines distributed on the middle portion of palpomere III and absent from palpomere II. Labroepipharynx 313 $(313 \pm 18 ; \mathrm{n}=12)$ long. Cibarium with four posterior teeth fused at the base and anterior teeth arranged in lateral sets (Fig. 8); pigment patch developed and posterior bulge well developed; arch complete. Pharynx unarmed. Labial sutures united. Maxilla: lacinia with six external teeth arranged in a longitudinal row and about 41 internal teeth. Hypopharynx with apicolateral teeth well delineated.

\section{Cervix: ventrocervical sensilla present.}

Thorax: mesonotum $530(529 \pm 24 ; \mathrm{n}=12)$ long. Pleurae with three proepimeral setae $(2-6 ; n=12), 14$ upper anepisternal setae $(14-25 ; n=12)$ and without metaepisternal setae. Setae present on the anterior katepisternum margin. Incomplete suture between katepimeron and metaepisternum present. Wing (Fig. 10): length 1,798 (1,762 $\pm 64 ; \mathrm{n}=12)$, width $520(506 \pm 25 ; \mathrm{n}=10)$. Length of vein sections: alpha $404(392 \pm 27 ; \mathrm{n}=11)$, beta $280(284 \pm$ $18 ; \mathrm{n}=11)$, gamma $385(288 \pm 65 ; \mathrm{n}=10)$, delta $110(117$ $\pm 24 ; \mathrm{n}=11)$, pi $160(140 \pm 34 ; \mathrm{n}=9)$, R5 1,139 $(1,126 \pm$ $44 ; n=10$ ). Legs (measures based on paratype 7) foreleg lost; midleg: length of femora 704, tibiae 833, basitarsi 480 and tarsi II $+\mathrm{III}+\mathrm{IV}+\mathrm{V}$ 614; hindleg: length of femora 757, tibiae 1046, basitarsi 552 and tarsi II + III + IV+V 658. Abdomen length 1,389 $(1,380 \pm 124 ; \mathrm{n}=11)$.

Spermathecae: spherical body (Fig. 11) (20 long x 19 wide) $(18 \pm 3 \times 19 \pm 2 ; \mathrm{n}=12)$; individual ducts smooth: length $76(78 \pm 9 ; \mathrm{n}=12)$, apical width $10(9 \pm 2 ; \mathrm{n}=12)$; common duct length: $29(31 \pm 3 ; \mathrm{n}=10)$, width (Fig. 11) $24(23 \pm 2 ; \mathrm{n}=7)$; ratio length of common duct/individual duct $2.64(2.5 \pm 0.4 ; \mathrm{n}=10)$. Cercus 54 long (45 $\pm 9 ; \mathrm{n}=12$ ).

Type-locality - Casa dos Padres, Vila Falcão, municipality of Lábrea (Figueira \& Silva, cols.).

Type data - Holotype male. Casa dos Padres, Vila Falcão, municipality of Lábrea, intradomicile, 13.XII.2010, 04:00 pm-07:00 am. Allotype female. Casa dos Padres, Vila Falcão, municipality of Lábrea, extradomicile,
13.XII.2010, 04:00 pm-07:00 am [Museum of Zoology, University of São Paulo (MZUSP), São Paulo, Brazil]. Paratypes, 11 males and 11 females [(MZUSP) and National and International Reference Center for Phlebotominae (sandflies) (CRNIF)/René Rachou Research Center (CPqRR)/Oswaldo Cruz Foundation]: one male and two females: Vila Falcão, Lábrea, peridomicile, 30.VIII.2010; one male: Vila Falcão, Lábrea, peridomicile, 30.IX.2010; four males and six females: Casa dos Padres, Vila Falcão, Lábrea, extradomicile, 13.XII.2010; one male and one female: Casa dos Padres, Vila Falcão, Lábrea, peridomicile, 14.XII.2010; one male: Casa dos Padres, Vila Falcão, Lábrea, peridomicile, 15.XII.2010; three males and one female: Casa dos Padres, Vila Falcão, Lábrea, extradomicile, 15.XII.2010; one female: Casa dos Padres, Vila Falcão, Lábrea, intradomicile, 13.XII.2010. The type material was captured by EAGF and GS. Type specimens are deposited in the entomological collections of the MZUSP, CRNIF/CPqRR.

Etymology - The name of this species is proposed as a noun (epithet) in apposition in reference to the indigenous people known as the Apurinã which inhabit the terrafirme forest which is now the municipality of Lábrea.

Taxonomic discussion - Among the Evandromyia (Aldamyia) species in which the male possesses a bifurcated aedeagus, the ventral margin of the paramere is without pre-apical lobe and the apex of the ejaculatory ducts are round-shaped with one distinct tooth, such as found in Ev. (A.) apurinan sp. nov., are Evandromyia (A.) andersoni (Le Pont \& Desjeux, 1988), Evandromyia (A.) sericea (Floch \& Abonnenc, 1944), Evandromyia (A.) sp. de Baduel (Floch \& Abonnenc, 1945) and Evandromyia (A.) walkeri (Newstead, 1914). Compared to these four species, the new taxon $E v$. (A.) apurinan is most similar to Ev. (A.) walkeri. However, Ev. (A.) apurinan and $E v$. (A.) walkeri may be distinguished from one another by the basal tuft of the gonocoxite, which is composed of eight $(8-10 ; \mathrm{n}=12)$ setae not arranged in parallel rows in Ev. (A.) apurinan and composed of more than $c a .18$ setae arranged in two parallel rows in Ev. (A.) walkeri, the latter arrangement of setae is also found in $E v$. (A.) andersoni, Ev. (A.) sericea and $E v$. (A.) sp. de Baduel. The ventral lobe of the aedeagus of Ev. (A.) walkeri is longer than the dorsal lobe, while the ventral lobe of the aedeagus of Ev. (A.) sericea is reduced in size when compared to the dorsal lobe and the ventral and dorsal lobes of $E v$. (A.) apurinan, Ev. (A.) andersoni and $E v$. (A.) sp. de Baduel are of equal lengths. In addition, $E v$. (A.) andersoni, Ev. (A.) sericea and Ev. (A.) sp. de Baduel can be distinguished from $E v$. (A.) apurinan by the presence of one-two isolated setae located in the middle of the dorsal margin of the paramere.

Among the species of Evandromyia (Aldamyia) described by their females in which the common duct of the spermathecae is shorter than the individual duct and without sclerotized external margins and the individual sperm ducts are more or less subequal in width throughout are Evandromyia (A.) evandroi (Costa Lima \& Antunes, 1936) and Evandromyia (A.) williamsi (Causey \& 
Arouck, Damasceno, 1945). However, the new species Ev. (A.) apurinan may be distinguished by the length of the common duct which is $1 / 4$ the length of individual duct, while this ratio is $1 / 6$ in the other two species. The body of the spermathecae of $E v$. (A.) apurinan and $E v$. (A.) williamsi are relatively large and bell-shaped, its length subequal to the width of the common duct, while in Ev. (A.) evandroi the body of the spermathecae is smaller and subspherical, its length much less than the width of the common duct. Finally, Ev. (A.) williamsi has a pale thorax and the thorax of Ev. (A.) apurinan and $E v$. (A.) evandroi are brown.
Sandflies collected in Lábrea - Overall, a total of 510 specimens (319 females and 191 males) were collected and 476 were identified to species level. They belonged to 26 species and represented 12 genera and three subtribes (Sergentomyiina, Lutzomyiina and Psychodopygina). Due to loss of structures of taxonomic importance, 15 specimens could only be identified to genus level and 19 specimens were too damaged to allow any identification (Table).

Most of the sandflies were collected from Vila Falcão $(\mathrm{n}=386 ; 75.7 \%)$, with a minority of the sandflies collected from Apairal $(n=96 ; 18.8 \%)$, Aldeia Irmã Cleusa $(n=$

TABLE

Species of sandfly collected in the municipality of Lábrea, state of Amazonas (AM), Brazil

\begin{tabular}{|c|c|c|c|c|c|c|c|c|c|c|}
\hline \multirow[b]{2}{*}{ Genus } & \multirow[b]{2}{*}{ Species } & \multicolumn{2}{|c|}{ Aldeia Castanheira } & \multicolumn{2}{|c|}{ Aldeia Irmã Cleusa } & \multicolumn{2}{|c|}{ Apairal } & \multicolumn{2}{|c|}{ Vila Falcão } & \multirow[b]{2}{*}{ Total } \\
\hline & & $\mathrm{M}$ & $\mathrm{F}$ & M & $\mathrm{F}$ & $\mathrm{M}$ & $\mathrm{F}$ & $\mathrm{M}$ & $\mathrm{F}$ & \\
\hline \multirow[t]{3}{*}{ Bichromomyia } & flaviscutellata & - & 1 & - & 5 & - & 3 & 2 & 8 & 19 \\
\hline & olmeca bicolor & - & - & - & - & - & 1 & - & - & 1 \\
\hline & sp. & - & - & - & - & - & 1 & - & - & 1 \\
\hline \multirow[t]{6}{*}{ Evandromyia } & bacula & - & - & - & - & - & 1 & - & - & 1 \\
\hline & saulensis & - & - & - & 2 & - & - & 3 & 13 & 18 \\
\hline & sipani $^{a}$ & - & - & - & - & - & - & 1 & - & 1 \\
\hline & sp. & - & - & - & - & - & 1 & - & - & 1 \\
\hline & sp. nov. & - & - & - & - & - & - & 13 & 15 & 28 \\
\hline & walkeri & - & - & - & - & - & - & 26 & 28 & 54 \\
\hline Lutzomyia & sherlocki & - & - & - & - & - & 3 & - & - & 3 \\
\hline Micropygomyia & rorotaensis & - & - & - & - & - & - & 14 & 36 & 50 \\
\hline \multirow[t]{4}{*}{ Nyssomyia } & antunesi & - & - & - & 11 & - & 4 & 97 & 115 & 227 \\
\hline & umbratilis & - & - & - & - & - & 3 & 1 & - & 4 \\
\hline & yuilli yuilli & - & - & - & - & - & 2 & - & - & 2 \\
\hline & sp. & - & - & - & - & - & - & - & 2 & 2 \\
\hline Pintomyia & christenseni & - & - & - & - & - & 2 & - & - & 2 \\
\hline Pressatia & trispinosa & - & - & - & - & 1 & - & - & - & 1 \\
\hline \multirow[t]{3}{*}{ Psathyromyia } & (Forattiniella) sp. & - & - & - & - & - & 1 & - & - & 1 \\
\hline & abunaensis & - & - & - & - & 1 & & - & - & 1 \\
\hline & campbelli & - & - & - & - & - & 1 & - & - & 1 \\
\hline \multirow[t]{5}{*}{ Psychodopygus } & ayrozai & - & - & - & - & - & 6 & - & 2 & 8 \\
\hline & claustrei & - & - & - & - & 1 & 7 & - & - & 8 \\
\hline & davisi & - & - & - & - & 1 & 10 & - & - & 11 \\
\hline & paraensis & - & - & - & - & - & 1 & - & - & 1 \\
\hline & sp. & - & - & - & - & - & 3 & - & 1 & 4 \\
\hline \multirow[t]{3}{*}{ Sciopemyia } & servulolimai & - & - & - & - & 2 & - & - & - & 2 \\
\hline & sordellii & - & - & - & - & - & 1 & - & 1 & 2 \\
\hline & $\mathrm{sp}$ & - & - & - & - & - & 1 & - & - & 1 \\
\hline Unidentifed genera & sp. & - & - & - & 8 & - & 5 & 3 & 3 & 19 \\
\hline \multirow[t]{3}{*}{ Trichophoromyia } & flochi $i^{b}$ & - & - & - & - & 1 & - & - & - & 1 \\
\hline & ubiquitalis & - & - & 1 & - & 22 & 3 & 1 & 1 & 28 \\
\hline & sp. & - & - & - & - & - & 5 & - & - & 5 \\
\hline \multirow[t]{2}{*}{ Viannamyia } & furcata & - & - & - & - & - & 1 & - & - & 1 \\
\hline & tuberculata & - & - & - & - & - & 1 & - & - & 1 \\
\hline Total & - & - & 1 & 1 & 26 & 29 & 67 & 161 & 225 & 510 \\
\hline
\end{tabular}

$a$ : new record for Brazil; $b$ : new record for AM; F: female; M: male. 
25, 5.3\%) and Aldeia Castanheira $(\mathrm{n}=1 ; 0.2 \%)$.

The following genera, which accounted for $90.2 \%$ of the total of sandflies collected, had the largest number of species collected: Evandromyia (5), Psychodopygus Mangabeira, 1941 (4) and Nyssomyia (3). The genus Bichromomyia Artemiev, 1991, Psathyromyia Barretto, 1962, Sciopemyia Barretto, 1962, Trichophoromyia Barretto, 1962 and Viannamyia Barretto, 1962 were represented by two species each. The remaining genera were represented by only one species each: Lutzomyia França, 1924, Micropygomyia Barretto, 1962, Pressatia Mangabeira, 1942 and Pintomyia Costa Lima, 1932.

The most abundant genera were Nyssomyia $(\mathrm{n}=325$; $63.7 \%)$ and Evandromyia $(103 ; 20.2 \%)$. Nyssomyia antunesi (Coutinho, 1939) was the most abundant sandfly species $(227 ; 44.5 \%)$, followed by Ev. walkeri (54; $10.6 \%$ ), Micropygomyia rorotaensis (Floch \& Abonnenc, 1944) (50; 9.8\%), Trichophoromyia ubiquitalis (Mangabeira, 1942) (28; 5.5\%) and Ev. apurinan Shimabukuro, Figueira \& Silva sp. nov. (28; 5.5\%). These five species comprised $75.9 \%$ of the total of sandflies collected.

Ten species were represented only by one specimen: Bichromomyia olmeca bicolor (Fairchild \& Theodor 1971), Psathyromyia abunaensis (Martins, Falcão \& Silva, 1965), Psathyromyia campbelli (Damasceno, Causey \& Arouck, 1945), Psychodopygus paraensis (Costa Lima, 1941), Trichophoromyia flochi (Abonnenc \& Chassignet, 1948), Viannamyia tuberculata (Mangabeira, 1941), Viannamyia furcata (Mangabeira, 1941), Pressatia trispinosa (Mangabeira, 1942), Evandromyia sipani (Fernández, Carbajal, Alexander \& Need, 1994) and Evandromyia bacula (Martins, Falcão \& Silva, 1965). Eleven species were represented by two-19 specimens each and comprised $15.5 \%$ of the total of sandflies collected.

Most of the sandflies were collected in the peridomicile $(232 ; 45.5 \%)$ and in the forest border $(226 ; 44.3 \%)$, followed by intradomicile $(52 ; 10.2 \%)$. The largest diversity was found in the forest border (25 species) and in the peridomicile (11 species); the intradomicile accounted for the smallest number of species collected (6).

Here we also report a new record in AM, Th. flochi collected at Apairal, and a new record for Brazil, Ev. sipani collected at Vila Falcão. Both species were collected in the peridomicile.

\section{DISCUSSION}

The sandflies collected from July-December 2009 and September-December 2010 in the municipality of Lábrea represent over $10 \%$ of the total of sandflies recorded in Brazil (Shimabukuro \& Galati 2010). Our results describe the composition of the sandfly fauna from the south of AM, which is becoming part of the "arc of deforestation", an area under strong anthropic pressure due to deforestation for logging and cattle ranching (Fearnside 2005). The majority of the sandflies were collected in Vila Falcão, which is expected as most of the collection effort was concentrated in this location, which is a nearby rural neighbourhood of Lábrea easily accessed by car. In contrast, the other three localities studied have limited access and can only be reached during dry months of the year.
Nyssomyia was the most abundant genus collected in our study mainly because of the dominance of $N y$. antunesi. This anthropophilic genus has been previously reported as highly abundant in other areas of AM (Barrett et al. 1996, Castellón et al. 2000, Dias-Lima et al. 2002, Feitosa \& Castellón 2006, Guerra et al. 2006, Silva et al. 2007). Varying degrees of environmental change caused by human activities might be responsible for the differences in the sandfly fauna composition found throughout the Amazon Region (Ready et al. 1986). For example, Psychodopygus is more abundant in non-disturbed primary forest, while Nyssomyia is more abundant in areas under human impact found in $\mathrm{AM}$, state of Acre (AC) and state of Mato Grosso (Azevedo et al. 2002, 2008, Alves et al. 2012). The most abundant sandfly species, $N y$. antunesi $(44.51 \%)$, is a suspected vector of Leishmania $(V$.$) lindenbergi Silveira, Ishikawa, Souza$ \& Lainson (Silveira et al. 2002) in PA. This sandfly has also been found infected with promastigotes, which did not produce skin lesions in hamsters and could possibly be Leishmania (Le.) infantum [syn. Le. (Le.) chagasi] (Ryan et al. 1984). In some areas of the Colombian Amazon Forest this species has developed intradomiciliary habits and is a suspected vector of Leishmania spp (Vásquez-Trujillo et al. 2008, Cabrera et al. 2012). Only five females from Nyssomyia umbratilis (Ward \& Fraiha, 1977) and Nyssomyia yuilli yuilli (Young \& Porter, 1972) were collected at the border of the forest at Apairal and one female of $N y$. umbratilis at Vila Falcão. $N y$. umbratilis is the main vector of $L$. (V.) guyanensis north of the Amazonas River and is the most abundant species sampled from the base of tree trunks during the day (Dias-Lima et al. 2002, Guerra et al. 2006). Ny. yuilli yuilli was found infected with Leishmania mexicana-like organisms (Arias et al. 1985) and this species has also been found in forest habitats in the states of Bahia (BA) and Espírito Santo where it has been implicated as a vector of Leishmania spp (Vexenat et al. 1986, Dias-Lima et al. 2003, Pinto et al. 2010). The low numbers of these two species collected in our study in the forest border, as opposed to the high number of $N y$. antunesi collected in intra and peridomiciliary locations implicates the latter in the transmission of ACL in Lábrea.

The other species we collected of medical importance include Th. ubiquitalis, incriminated as a vector of Leishmania (Viannia) lainsoni Silveira, Shaw, Braga \& Ishikawa, 1987 (Silveira et al. 1991, Lainson et al. 1992), Bichromomyia flaviscutellata (Mangabeira, 1942), the main vector of Leishmania (Leishmania) amazonensis Lainson \& Shaw, 1972, and species from the genus Psychodopygus: Psychodopygus ayrozai (Barretto \& Coutinho, 1940), Psychodopygus davisi (Root, 1934) and Psychodopygus claustrei (Abonnenc, Léger \& Fauran, 1979), which are associated with ACL transmission in both enzootic and zoonotic cycles in the Amazon Region (Rangel \& Lainson 2003a, Rotureau 2006).

Despite the fact that most collection efforts were spent in Vila Falcão, all the four areas surveyed in this study have reported autochthonous cases of ACL and ML. The inhabitants of three localities (Apairal, Aldeia Irmã Cleusa and Aldeia Castanheira) are involved in 
forest activities such as açaí and Brazil nut collection, hunting and fishing. Most of these inhabitants also live in wooden traditional houses built very close to the forest. Three cases of ML have been reported from Aldeia Castanheira, an indigenous community with approximately 60 people (FUNASA 2012, SEMSA 2012). Guerra et al. (2011) reported Lábrea as the municipality with the highest number of ML cases in AM, which are mainly associated with activities related to exploitation of forest products.

Despite the low number of specimens collected, we found a high diversity of species, with 26 species collected, most of them collected at the border of the forest. These collections also included one new species, as well as two species which had not been previously recorded, either in AM or the whole of Brazil. The new record for AM, Th. flochi, was collected at Apairal and has been previously recorded in a discontiguous region spanning, in the north, the Amazon Forest of French Guyana and, in the south, in BA, AC and RO (Galati 2003, Castellón 2009). Our record for AM fills in this gap, in the previously discontinuous description of the distribution of this species, between the south of the Brazilian Amazon and French Guyana. In this context, it is worth mentioning that a specimen of Th. flochi was found by one of us (PHFS) at the MZUSP. The specimen was collected by Dr RG Damasceno in the municipality of Coari, Fonte Boa, AM, in April 1943, but was misidentified by him as Trichophoromyia octavioi (Vargas, 1949). Even though Th. flochi and Th. octavioi are similar, they can be distinguished by the apical lobe of the paramere, which is glabrous in Th. flochi and is covered by setae in Th. octavioi. The new record for Brazil, Ev. sipani, was collected at Vila Falcão and has only been previously recorded in the Amazonian lowlands of Peru and Colombia (Fernandez et al. 1994, Barreto et al. 2000). With these two new records, the total of recorded sandfly species in AM increases from 131 to 133 .

Entomological surveillance of sandflies is very important in providing information on the fauna composition, bio-ecology and behaviour of vectors of Leishmania. In our study, the observed presence and high abundance of $N y$. antunesi in intra and peridomiciliary locations suggests that this species may be a vector of ACL in Lábrea.

\section{ACKNOWLEDGEMENTS}

To SEMSA, Lábrea, for support during fieldwork, and to Dr Luke Baton, for revising and commenting on draft versions of this paper.

\section{REFERENCES}

Alves VR, Freitas RA, Santos FL, Oliveira AFJ, Barrett TV, Shimabukuro PHF 2012. Sand flies (Diptera, Psychodidae, Phlebotominae) from Central Amazonia and four new records for the state of Amazonas, Brazil. Rev Bras Entomol 56: 220-227.

Arias JR, Freitas RA 1978. Sobre os vetores da leishmaniose cutânea na Amazônia Central do Brasil. 2. Incidência de flagelados em flebótomos selváticos. Acta Amazon 8: 387-396.

Arias JR, Miles MA, Naiff RD, Povoa MM, de Freitas RA, Biancardi CB, Castellon EG 1985. Flagellate infections of Brazilian sand flies (Diptera, Psychodidae). Isolation in vitro and biochemical identification of Endotrypanum and Leishmania. Am J Trop Med Hyg 34: 1098-1108.

Azevedo ACR, Costa SM, Pinto MCG, Souza JL, Cruz HC, Vidal J, Rangel EF 2008. Studies on the sandfly fauna (Diptera: Psychodidae: Phlebotominae) from transmission areas of American cutaneous leishmaniasis in state of Acre, Brazil. Mem Inst Oswaldo Cruz 103: 760-767.

Azevedo ACR, Lainson R, Souza AA, Fe NF, Feliciangeli DM, Meneses CRV, Rangel EF 2002. Comparative studies of populations of Lutzomyia umbratilis (Diptera: Psychodidae) in Brazil and Venezuela. J Med Entomol 39: 587-600.

Barreto M, Burbano ME, Barreto P 2000. Lutzomyia sand flies (Diptera: Psychodidae) from middle and lower Putumayo department, Colombia, with new records to the country. Mem Inst Oswaldo Cruz 95: 633-639.

Barrett TV, de Freitas RA, Albuquerque MIC, Guerrero JCH 1996. Report on a collection of Lutzomyia sand flies (Diptera: Psychodidae) from the middle Solimões (Amazonas, Brazil). Mem Inst Oswaldo Cruz 91: 27-35.

Bermúdez H, Dedet JP, Falcao AL, Feliciangeli D, Rangel EF, Ferro C, Galati EAB, Gomez EL, Herrero MV, Hervas D, Lebbe J, Morales A, Ogusuku E, Perez E, Sherlock I, Vignes R, Woff M, CIPA Group 1991. Proposition of a standard description for phlebotomine sandflies. CIPA Group. Parassitologia 33: 127-135.

Cabrera OL, Mosquera L, Santamaría E, Ferro F 2012. Flebótomos (Diptera: Psychodidae) del departamento de Guaviare, Colombia, con nuevos registros para el país. Biomedica 28: 73-86.

Castellón EG 2009. Lutzomyia sand flies in the Brazilian Amazon basin (Diptera: Psychodidae), INPA, Manaus, 202 pp.

Castellón EG, Fe NF, Buhrnheim PFFFA 2000. Flebotomíneos (Diptera, Psychodidae) na Amazônia. II. Listagem as espécies coletadas na bacia petrolífera no Rio Urucu, Amazonas, Brasil, utilizando diferentes armadilhas e iscas. Rev Bras Zool 17: 455-462.

Dias-Lima A, Bermudez EC, Medeiros JF, Sherlock I 2002. Vertical stratification of phlebotomine sandfly fauna (Diptera, Psychodidae) in a primary non-flooded forest of the Central Amazon, Amazonas state, Brazil. Cad Saude Publica 18: 823-832.

Dias-Lima AG, Guedes MLS, Sherlock IA 2003. Horizontal stratification of the sand fly fauna (Diptera: Psychodidae) in a transitional vegetation between Caatinga and tropical rain forest, state of Bahia, Brazil. Mem Inst Oswaldo Cruz 98: 733-737.

Fearnside PM 2005. Deforestation in Brazilian Amazonia: history, rates and consequences. Conserv Biol 19: 680-688.

Feitosa MAC, Castellón EG 2006. Fauna de flebotomíneos (Diptera: Psychodidae) em fragmentos de floresta ao redor de conjuntos habitacionais na cidade de Manaus, Amazonas, Brasil. I. Estratificação vertical. Acta Amazon 36: 539-548.

Fernandez R, Carbajal F, Alexander B, Need JT 1994. Description of Lutzomyia (Evandromyia) sipani, a new species of sand fly (Diptera: Psychodidae) from Loreto department, Peru. Mem Inst Oswaldo Cruz 89: 167-169.

Forattini OP 1973. Entomologia Médica. Psychodidae. Phlebotominae. Leishmanioses. Bartonelose, Vol. IV, Edgar Blucher, São Paulo, 658 pp.

FUNASA - Fundação Nacional de Saúde 2012. Relatório de LTA entre indígenas, Funasa, Lábrea, 1-3.

Galati EAB 2003. Classificação de Phlebotominae. In EF Rangel, R Lainson (orgs.), Flebotomíneos do Brasil, Fiocruz, Rio de Janeiro, p. 23-175.

Guerra JAD, Prestes SR, Silveira H, Coelho LIDR, Gama P, Moura A, Amato V, Barbosa MDV, Ferreira LCD 2011. Mucosal leish- 
maniasis caused by Leishmania (Viannia) braziliensis and Leishmania (Viannia) guyanensis in the Brazilian Amazon. PLoS Negl Trop Dis 5: e980-e980.

Guerra JAO, Ribeiro JAS, Coelho LIARC, Barbosa MGV, Paes MG 2006. Epidemiologia da leishmaniose tegumentar na Comunidade São João, Manaus, Amazonas, Brasil. Cad Saude Publica 22: $2319-2327$

IBGE - Instituto Brasileiro de Geografia e Estatística 2012. [homepage on the Internet]. Cidades. Brasília: IBGE [updated $2012 \mathrm{Apr}$ 1; cited 2011 Dec 1]. Available from: ibge.gov.br/cidadesat/topwindow.htm?1.

Justiniano SC, Chagas AC, Pessoa FA, Queiroz RG 2004. Comparative biology of two populations of Lutzomyia umbratilis (Diptera: Psychodidae) of Central Amazonia, Brazil under laboratory conditions. Braz J Biol 64: 227-235.

Lainson R, Shaw JJ, Souza AAA, Silveira FT, Falqueto A 1992. Further observations on Lutzomyia ubiquitalis (Psychodidae: Phlebotominae), the sandfly vector of Leishmania (Viannia) lainsoni. Mem Inst Oswaldo Cruz 87: 437-439.

MS/SINAN - Ministério da Saúde/Sistema de Informação de Agravos de Notificação Brasil 2012. [homepage on the Internet]. O que é o SINAN [updated 2012 Jan 1; cited 2011 Dec 1]. Available from: dtr2004.saude.gov.br/sinanweb/.

Pinto IS, dos Santos CB, Ferreira AL, Falqueto A 2010. Richness and diversity of sand flies (Diptera, Psychodidae) in an Atlantic rainforest reserve in south-eastern Brazil. J Vector Ecol 35: 325-332.

Rangel EF, Lainson R 2003a. Ecologia das leishmanioses. In EF Rangel, R Lainson (org.), Flebotomíneos do Brasil, Fiocruz, Rio de Janeiro, p. 291-309.

Rangel EF, Lainson R 2003b. Flebotomíneos do Brasil, Fiocruz, Rio de Janeiro, 367 pp.

Ready PD, Lainson R, Shaw JJ, Ward RD 1986. The ecology of Lutzomyia umbratilis Ward \& Fraiha (Diptera, Psychodidae), the major vector to man of Leishmania braziliensis guyanensis in northeastern Amazonian Brazil. Bull Entomol Res 76: 21-40.

Romero GAS, Ishikawa E, Cupolillo E, Toaldo CB, Guerra MVF, Paes MG, Macedo VO, Shaw JJ 2002. The rarity of infection with Leishmania (Viannia) braziliensis among patients from the Manaus region of Amazonas state, Brazil, who have cutaneous leishmaniasis. Ann Trop Med Parasitol 96: 131-136.

Rotureau B 2006. Ecology of the Leishmania species in the Guianan ecoregion complex. Am J Trop Med Hyg 74: 81-96.

Ryan L, Silveira FT, Lainson R, Shaw JJ 1984. Leishmanial infections in Lutzomyia longipalpis and Lu. antunesi (Diptera: Psychodidae) on the island of Marajó, Pará state, Brazil. Trans R Soc Trop Med Hyg 78: 547-548.

SEMSA - Secretaria Municipal de Saúde Lábrea 2012. Relatório sobre a leishmaniose tegumentar americana em Lábrea, SEMSA, Lábrea, 4 pp.

Shimabukuro PHF, Galati EAB 2010. Checklist of Phlebotominae (Diptera, Psychodidae) from São Paulo state, Brazil, with notes on their geographical distribution. Biota Neotrop 11: 1-20.

Silva DF, Freitas RA, Franco AMR 2007. Diversity and abundance of phlebotomine of the genus Lutzomyia (Diptera: Psychodidae) in areas of forest in the northeast of Manacapuru, Amazonas state, Brazil. Neotrop Entomol 36: 138-144.

Silveira FT, Ishikawa EAY, de Souza AAA, Lainson R 2002. An outbreak of cutaneous leishmaniasis among soldiers in Belém, Pará state, Brazil, caused by Leishmania (Viannia) lindenbergi n. sp - A new leishmanial parasite of man in the Amazon Region. Parasite 9: 43-50.

Silveira FT, Souza AAA, Lainson R, Shaw JJ, Braga RR, Ishikawa EEA 1991. Cutaneous leishmaniasis in the Amazon Region: natural infection of the sandfly Lutzomyia ubiquitalis (Psychodidae: Phlebotominae) by Leishmania (Viannia) lainsoni in Pará state, Brazil. Mem Inst Oswaldo Cruz 86: 127-130.

Vásquez-Trujillo A, Santamaría-Herreño E, González-Reina AE, Buitrago-Álvarez LS, Góngora-Orjuela A, Cabrera-Quintero OL 2008. Lutzomyia antunesi, probable vector de leishmaniasis cutánea en el área rural de Villavicencio. Rev Salud Publica (Bogota) 10: 625-632.

Vexenat JA, Barretto AC, Cuba CC, Marsden PD 1986. Características epidemiológicas da leishmaniose tegumentar americana em uma região endêmica do estado da Bahia: III. Fauna flebotomínica. Mem Inst Oswaldo Cruz 81: 293-301. 